\title{
Katkıların Kuyu Çimentosunun Donma Sıcaklığında Sebep Olduğu Değişimlerin Koruma Borusu Tasarımına Etkisinin İncelenmesi
}

\author{
Mustafa Hakan ÖZYURTKAN*, Sardar ASADOV \\ İstanbul Teknik Üniversitesi, Petrol ve Doğal Gaz Mühendisliği Bölümü, İstanbul \\ (ORCID: 0000-0002-3105-2271) ORCID: 0000-0001-7372-0330)
}

\begin{abstract}
$\ddot{O} z$
Kuyu çimentosu donma süreci boyunca iç ve dış değiş̧imlerden etkilenmektedir. Bu değişimler bu süreçte çimentonun formasyon ve koruma borusuna bağlanma sorunlarına sebep olabilmektedir. Bu bağlanma problemi sonucunda koruma borusu arkasından akışlara sebep olabileceği gibi, kuyunun kaybedilmesine kadar giden sorunlara sebebiyet verebilir. Kuyu çimentosunun donma sürecinde ekzotermik bir reaksiyon geliştirdiği bilinmektedir. Çimento ve su karışımına ek olarak, çimentonun akmazlık ve su kaybı gibi özelliklerini ayarlamak için kullanılan katkı maddelerinin bu ekzotermik reaksiyon üzerinde etkileri vardır. Özellikle oluşan donma sırasında ortam sıcaklık değişimleri gözlenmektedir. Bu sıcaklık değişimlerinin koruma borusu tasarımında da dikkate alınması gerekmektedir. Aksi takdirde kuyu stabilitesinde bozulmalara neden olabilir. Bu çalışmada, katkılı kuyu çimentosunun donma sıcaklığında sebep olduğu değişimlerin koruma borusu tasarımına etkisi incelenmiştir. Bunun için daha önceki çalışmalarda rapor edilmiş olan yüksek, orta ve düşük sıcaklık değişimine sahip çimento kompozisyonlarından elde edilen veriler kullanılmıştır. Çimento şerbetlerinde katkı maddeleri nedeniyle oluşan termal yüklerin koruma borusu tasarımı için etkileri hesaplanmıştır. Çalışmada farklı koruma borusu ve farklı derinliğe sahip kuyular için hesaplamalar yapılmıştır. Yüksek sıcaklık değişimlerinde koruma boruları için her iki uçta da kompresif gerilmenin daha etkin olduğu sonucuna varılmıştır. Özellikle koruma borularındaki yüklerin sıkışmadan gerilmeye geçtiği bölgelerde bu etki boruların gerilme stabiletelerini etkileyebilir. Koruma borusu tasarımı yapılırken bu farkında göz önünde bulundurulması gerekebilir.
\end{abstract}

Anahtar kelimeler: Kuyu çimentosu, çimento katkı maddeleri, koruma borusu tasarımı, katkı maddelerinin hidrasyon 1sıs1 etkileri.

\section{Investigation of the Effect of the Change of the Well Cement Setting Temperature Caused by Additives on Casing Design}

\begin{abstract}
The well cement is affected by inner and outer alterations. Such alterations may result in bonding problems between formation and casing. This problem may cause not only fluid flow behind the casing but also losing the well. That is a well-known fact that the setting reaction of cement is an exothermic process. In order to regulate some properties of well cement such as viscosity and water loss, some additives are used and these additives have effect on the exothermic reaction. Especially, the change in temperature during setting is observed. These changes in temperature must be considered during casing design procedure. Otherwise, such situation may deteriorate the stability of the well. This study investigates the effect of the change of the well cement setting temperature caused by additives on casing design. In order to perform the study, the previously reported temperature data obtained from cement samples with different compositions are used for high, medium and low temperature change conditions. The thermal loads caused by additives in cement slurry are calculated for casing design. During the study, different types of casings are considered in computations for wells having different depths. For cases experiencing high temperature changes, it is indicated that compressive tension is more dominant at both ends of casings. Especially, the change in temperature caused by additives may affect the tension stability of the casings for the sections where the load passes through compression to tensile. Such situations may be considered while making the casing design.
\end{abstract}

Keywords: Well cement, cement additives, casing design, the effect of additives on thermal hydration.

"Sorumlu yazar: ozyurtkan@itu.edu.tr

Geliş Tarihi: 20.01.2020, Kabul Tarihi: 17.06.2020 


\section{Giriş}

Çimentolama, önemli sondaj ve kuyu tamamlama operasyonlarından birisidir. Çimento petrol, doğal gaz ve jeotermal sektöründe kuyunun sondajı ve tamamlanması sırasında farklı şekillerde kullanılmaktadır. Kuyuya indirilen koruma boruları ile formasyon arasındaki anülüs olarak adlandırılan boşluk doldurularak sondaj dizisinin yerleştirilmesinde, çamur kaçaklarının önlenmesinde, formasyonlardan kuyu aracılığıyla yüzeye kontrolsüz akışkan akışının önlenmesinde, kuyuların terk edilmesinde ve artık üretim yapılmayan formasyonların kapatılmasında kullanılır [1].

Kuyuya yerleştirilen koruma boruları indirildikleri derinlik ve indirilme sıralarına göre; kılavuz boru, yüzey koruma borusu, üretim koruma borusu, ara koruma borusu gibi farklı adlar alabilmektedir. Koruma boruları indirildikleri derinliğe kadar çimentolanabileceği gibi kısmi olarak ta çimentolanabilmektedir [2].

Petrol sektöründe kullanılan çimentolar, API (American Petroleum Institute) tarafindan farklı özelliklere sahip olarak A'dan H'ye kadar sinıflandırılmaktadır. Genellikle G ve H Sinıfı olarak belirtilen çimentolar kullanılmaktadır. Bununla beraber çimentonun kullanılacağ sıcaklığına veya basıncına göre su ve katkı maddeleri eklenerek istenen özellikler sağlanmaya çalışılmaktadır. Bu maddeler ekseriyetle katı halde ve toz şeklindedir ve çimentonun yoğunluk, akmazlık, donma zamanı ve su kaybı gibi özelliklerini kontrol etmek amacıyla kullanılmaktadır [3]. Sıcaklık arttıkça çimento şerbeti hidrate olur ve daha hızlı sertleşir. Bu sebeple yüzeyde tasarlanan çimento karışımının pompalanabilir olması ve reolojisinin buna göre ayarlanması gerekir. Bu yüzden çimento karışımının akmazlığını kontrol etmek amacıyla katkı maddeleri kullanılmaktadır. Sıcaklıktaki değişimler bu amaçla kullanılan katkı maddelerinin etkinliğini değiştirmektedir [4].

Çimentonun hidratasyonu ekzotermik bir prosestir. Çimentonun donması sırasında 1s1 salınmaktadır. Çimentonun her bir bileşeni bu bağlamda etkindir. Çimentonun donma sürecinde etkin olan bileşenler sırasıyla; Kalsiyum Alüminatlar (C3A (Tricalcium Silicate) and C4AF (Tetracalcium Aluminoferrite)), ve kalsiyum silikatlar (C3S (Tricalcium Silicate) and C2S (Dicalcium Silicate))'dır [5]. Çimentonun yapısı koruma borusu ve formasyona göre farklı termal genleşme ve elastik özelliklere sahiptir. Bu farklı yapısından dolayı koruma borusu ve formasyon arasında mikro-anülüs denen kanallar oluşmasına sebep olabilir [6]. Çimentonun donması sırasında kuyu çevresinde yüksek miktarda 1sı salınımı olmaktadır. Gerçekleştirilmiş olan deneysel çalışmalar ve saha ölçümlerinde koruma borusu arkasında çimentonun donma sürecinde yüksek miktarda 1sı akışı tespit edildiği belirtilmiştir. Sicaklıktaki bu değişimler ortama ekstra stres yüklemektedir [7]. Bu stres yüklemesi çimento bünyesinde mikro ve makro çatlaklara sebep olabilir. Kuyu çimentosu şerbeti hazırlanırken sıklıkla kullanılan katkı maddeleri akmazlık ve su kaybı sağlayıcı maddelerdir. Bu maddelerin kullanımı çimentonun yapısını kimyasal ve mekanik olarak etkilemektedir. Bu etkilerin dikkate alınmaması durumunda hazırlanmış olan çimento şerbeti istenen özelliklere sahip olmayabilir ve bu durum kuyu şartlarında çimentonun görevlerini yerine getirememesine sebep olabilir [8]. Daha önce gerçekleştirilmiş olan bir çalışmada sektörde sıklıkla kullanılan akmazlık ve su kaybı sağlayıcı katkı maddelerinin çimentonun donma sıcaklığını ciddi oranda arttırdığ $1\left(\sim 76^{\circ} \mathrm{C}\right)$ tespit edilmiştir. Bu iki katkı maddesinin ayrı ayrı ve beraber kullanılmaları durumunda dahi yüksek sıcaklıklar gözlenmiştir. Gerçekleştirilecek olan tasarımlarda bu durumun göz ardı edilmesi kuyu stabilitesi sorunlarına neden olabilir [9]. Kuyu çevresinde oluşan sıcaklık değişiminin koruma boruları üzerine de olumsuz etkileri olmaktadır. Koruma boruları sıcaklık ile ekstra yükler altına girmektedir. Koruma borusunun yerleştirilme durumuna göre bu yükler ekstra kompresif ve gerilme yükleri olarak etkiyebilir [10]. Özellikle çimentodan kaynaklı sıcaklık dalgalanmalarının bu yüklere sebep olabileceği öngörülmektedir.

$\mathrm{Bu}$ çalışma daha önce raporlanmış olan çimento katkı maddeleri kaynaklı oluşan sıcaklık değişimlerinin farklı derinlikteki kuyu ve farklı özellikteki koruma borularının stres yüklerine olan etkisinin incelenmesini içermektedir. Koruma borularının yükleri üzerinde oluşacak olan çimentodaki sıcaklık değişimi kaynaklı değişimlerin incelenmesi ve sonuçların ortaya konulması amaçlanmıştır.

\section{Metot}

Çalışmada daha önce belirtilmiş olan katkılı çimentonun donma sürecinde oluşmuş olan sıcaklık değerleri baz alınmıştır [9]. Buna ek olarak ölçülen sıcaklıklar sıcaklık farkı olarak hesaplamalar 
gerçekleştirilmiştir. Oluşan sıcaklık farklılıkları sırasıyla $53{ }^{\circ} \mathrm{C}, 40{ }^{0} \mathrm{C}$ ve $25{ }^{0} \mathrm{C}$ olarak ele alınmıştır. Hesaplamalarda API tarafindan K-55, C-95 ve P-110 tip olarak sinıflandırması yapılan ve sektörde sıklıkla kullanılan ve farklı nominal ağırlıklara sahip üç farklı koruma borusu kullanılmıştır. Bununla beraber hesaplamalar $3000 \mathrm{ft} \mathrm{(} \mathrm{1000} \mathrm{m),} 10000 \mathrm{ft}(\sim 3300 \mathrm{~m})$ ve $15000 \mathrm{ft}(\sim 5000 \mathrm{~m})$ 'lik kuyu derinlikleri kullanılarak ve koruma boruları anülüsünün yüzeye kadar çimentolandığı varsayılarak gerçekleştirilmiştir.

Her bir koruma borusu için kullanılan nominal ağırlık ve çap değerleri, koruma borusu minimum performans özellikleri tablolarından alınmıştır [1]. Hesaplamalarda kullanılan bu değerler Tablo 1'de verilmektedir.

Tablo 1. Hesaplamalarda kullanılan koruma borularının çap ve nominal ağıllık değerleri

\begin{tabular}{cccc}
\hline $\begin{array}{c}\text { Diş Çap } \\
\text { (in.) }\end{array}$ & $\begin{array}{c}\mathrm{K}-55 \\
(\mathrm{lb} / \mathrm{ft})\end{array}$ & $\begin{array}{c}\mathrm{C}-95 \\
(\mathrm{lb} / \mathrm{ft})\end{array}$ & $\begin{array}{c}\mathrm{P}-110 \\
(\mathrm{lb} / \mathrm{ft})\end{array}$ \\
\hline \multirow{2}{*}{7} & 20 & 32 & 32 \\
& 23 & 35 & 35 \\
& 26 & 38 & 38 \\
\hline \multirow{2}{*}{$95 / 8$} & 36 & 43.5 & 43.5 \\
& 40 & 47 & 47 \\
& & 53.5 & 53.5 \\
\hline \multirow{2}{*}{$133 / 8$} & 54.5 & 68 & 68 \\
& 61 & 72 & 72 \\
\hline
\end{tabular}

\section{Bulgular ve Tartışma}

Tablo 1'de verilmiş olan her bir tip koruma borusu, koruma borusunun her bir nominal ağırlığı ve üç farklı sıcaklık değişimi ele alınarak stres değerleri sırasıyla hesaplanmıştır. Tablo 2'de K-55 tipi koruma borusu için yapılmış olan stres hesapları verilmektedir. Tablo 2 verilerine göre erken dönem sıcaklık değişimlerinin koruma borusu stresi üzerine etkileri açıkça görülmektedir. Koruma borusu tabanındaki aksiyal gerilmeler koruma borusu çapı ve nominal ağıllıklarından ziyade sıcaklık değişiminden oluşmaktadır. Sıcaklık değişimindeki düşüş ve tabandaki aksiyal gerilmeler ters orantılıdır. Çimentodan kaynaklı oluşacak olan $53{ }^{\circ} \mathrm{C}^{\prime}$ lik bir sıcaklık değişimi için $3000 \mathrm{ft}$ derinlikteki stres değeri - 10971 olarak hesaplanmıştır. Bu değer diğer durumlar için de aynıdır. Farklı sıcaklık değişim değerlerinde de her bir derinlik için aynı değer hesaplanmaktadır.

Tabandaki koruma borusu gerilme etkilerinin aksine yukarıdaki değerlerde aksiyal gerilme koruma borularının nominal ağırlıklarına, boruların uzunluklarına ve sıcaklıktaki değişimlere bağlıdır. $53{ }^{\circ} \mathrm{C}^{\prime}$ lik sıcaklık değişimi göz önüne alındığında, nominal ağırlıklar arttıkça yukarıdaki aksiyal gerilme artmaktadır. Bir başka deyişle, kompresif yükler azalmakta, çekme gerilim yükleri artmaktadır. Bununla birlikte, koruma borusunun uzunluğu arttıkça yukarıdaki çekme gerilmesi de artmaktadır. Farklı sıcaklık değişimleri için hesaplanmış olan yükler karşılaştırıldığında, sıcaklık değişimi arttıkça K-55 tip koruma borusundaki gerilmelerin arttığı söylenebilir. Bunun sonucu olarak ta kompresif yükler artmaktadır.

$53{ }^{\circ} \mathrm{C}$ ve $40{ }^{\circ} \mathrm{C}$ 'lik sıcaklık değişimlerinin olduğu durumlar karşılaştırıldığında artan sıcaklık değişiminin koruma borusu üzerinde daha fazla strese sebep olduğu gözlenmektedir. Bunun sonucu olarak ta kompresif yükler artmaktadır. Aksiyel gerilmenin en yüksek olduğu durum beklendiği gibi 53 ${ }^{0} \mathrm{C}$ 'lik değişimin olduğu ve koruma borusunun nominal ağırlığının $54.5 \mathrm{lb} / \mathrm{ft}$ ve çapının da $13^{3 / 8}$ inç olduğu durumdur. Benzer şekilde hesaplamalar C-95 tip koruma borusu için gerçekleştirilmiştir. Hesaplanmış olan gerilme değerleri Tablo 3 'te verilmektedir. Koruma borusu tipinden bağımsız olduğu kabul edildiğinden tabandaki gerilme değeri aynı şekilde -10971 psi olarak hesaplanmıştır. Koruma borusunun her iki ucunda da kompresif yüklerin etkin olduğu görülmektedir. Aksiyel gerilmenin en yüksek olduğu durum beklendiği gibi $53{ }^{\circ} \mathrm{C}^{\prime}$ lik değişimin olduğu ve koruma borusunun nominal ağırlı̆̆ının $54.5 \mathrm{lb} / \mathrm{ft}$ ve çapının da $13^{3 / 8}$ inç olduğu durumdur. Koruma borusu uzunluğu arttıkça aksiyal gerilme değerlerinde azalama olduğu görülmektedir. Koruma borusunun yüzeye yakın bölümlerinde değişen sıcaklıkla beraber kompresif gerilme değerlerinde ciddi değişimler olduğu hesaplanmıştır. Sıcaklık değişiminin $53{ }^{\circ} \mathrm{C}$ ve $25{ }^{\circ} \mathrm{C}$ olduğu koşullar karşılaştırıldığında 6800 psi değerlerine varan gerilme farklılıkları olmaktadır. Bununla beraber, özellikle düşük sıcaklıklardaki koşullarda, aksiyal gerilmenin kompresiften çekme gerilmesine doğru geçiş yaptığı görülmektedir. $10000 \mathrm{ft}$ ve $15000 \mathrm{ft}$ 
derinlikteki kuyular için yapılan hesaplamalarda koruma borusunun çimentodan kaynaklı sıcaklık değişimi boyunca gerilme etkisinde olduğu görülmektedir. Aynı sıcaklık değişimleri için hesaplamalar P-110 tipi koruma borusu için de tekrarlanmıştır. Sonuçlar beklendiği üzere diğer iki koruma borusu tipiyle benzerlik göstermektedir. Diğer koruma borusu tiplerinden farklı olarak sıcaklık değişiminin 40 ${ }^{0} \mathrm{C}$ olduğu şartlarda dahi çekme gerilmesinin etkin olduğu görülmektedir. P-110 tipi koruma borusu için hesaplanmış olan değerler Tablo 4'te verilmektedir.

Tablo 2. Farklı nominal ağırlıklara (lb/ft) sahip K-55 Tip Koruma Borusu ve farklı sıcaklık değişimleri için

\begin{tabular}{cccccccccc}
\multicolumn{10}{c}{ hesaplanan psi biriminden stres değerleri } \\
\hline$\Delta \mathrm{T}\left({ }^{\circ} \mathrm{C}\right)$ & $\begin{array}{c}\text { Derinlik } \\
\mathrm{ft})\end{array}$ & 20 & 23 & 26 & 36 & 40 & 54.5 & 61 & 68 \\
\hline \multirow{6}{*}{53} & 0 & -9411 & -9178 & -8944 & -9487 & -9322 & -9807 & -9667 & -9519 \\
& 3000 & -10971 & -10971 & -10971 & -10971 & -10971 & -10971 & -10971 & -10971 \\
& 0 & -5774 & -4995 & -4216 & -6023 & -5473 & -7092 & -6630 & -6131 \\
& 10000 & -10971 & -10971 & -10971 & -10971 & -10971 & -10971 & -10971 & -10971 \\
& 0 & -3177 & -2006 & -8371 & -3549 & -2725 & -5153 & -4459 & -3711 \\
& 15000 & -10971 & -10971 & -10971 & -10971 & -10971 & -10971 & -10971 & -10971 \\
\hline \multirow{4}{*}{40} & 0 & -6721 & -6487 & -6253 & -6796 & -6631 & -7116 & -6978 & -6828 \\
& 3000 & -8280 & -8280 & -8280 & -8280 & -8280 & -8280 & -8280 & -8280 \\
& 0 & -3083 & -2304 & -1524 & -3332 & -2782 & -4401 & -3938 & -3440 \\
& 10000 & -8280 & -8280 & -8280 & -8280 & -8280 & -8280 & -8280 & -8280 \\
& 0 & -485 & 685 & 1854 & -858 & -34 & -2462 & -1768 & -1020 \\
& 15000 & -8280 & -8280 & -8280 & -8280 & -8280 & -8280 & -8280 & -8280 \\
\hline \multirow{6}{*}{25} & 0 & -3616 & -3382 & -3148 & -3961 & -3526 & -4011 & -3873 & -3723 \\
& 3000 & -5175 & -5175 & -5175 & -5175 & -5175 & -5175 & -5175 & -5175 \\
& 0 & 22 & 801 & 1581 & -227 & 323 & -1296 & -833 & -335 \\
& 10000 & -5175 & -5175 & -5175 & -5175 & -5175 & -5175 & -5175 & -5175 \\
& 0 & 2620 & 3790 & 4959 & 2247 & 3071 & -644 & 1337 & 2085 \\
& 15000 & -5175 & -5175 & -5175 & -5175 & -5175 & -5175 & -5175 & -5175 \\
\hline
\end{tabular}

Tablo 3. Farklı nominal ağırlıklara (lb/ft) sahip C-95 Tip Koruma Borusu ve farklı sıcaklık değişimleri için hesaplanan psi biriminden stres değerleri

\begin{tabular}{cccccccccc}
\hline $\begin{array}{c}\Delta \mathrm{T} \\
\left({ }^{\circ} \mathrm{C}\right)\end{array}$ & Derinlik (ft) & 32 & 35 & 38 & 43.5 & 47 & 53.5 & 68 & 72 \\
\hline & 0 & -8476 & -8242 & -8008 & -9177 & -9033 & -9765 & -9519 & -9433 \\
& 3000 & -10971 & -10971 & -10971 & -10971 & -10971 & -10971 & -10971 & -10971 \\
53 & 0 & -2656 & -1876 & -1097 & -4992 & -4511 & -3618 & -6131 & -5846 \\
& 10000 & -10971 & -10971 & -10971 & -10971 & -10971 & -10971 & -10971 & -10971 \\
& 0 & 1501 & 2670 & 3840 & -2003 & -1281 & 58 & -3711 & -3284 \\
& 15000 & -10971 & -10971 & -10971 & -10971 & -10971 & -10971 & -10971 & -10971 \\
\hline 0 & -5785 & -5551 & -5318 & -6486 & -6342 & -6074 & -6828 & -6743 \\
& 3000 & -8280 & -8280 & -8280 & -8280 & -8280 & -8280 & -8280 & -8280 \\
40 & 0 & 35 & 814 & 1595 & -2301 & -1820 & -927 & -3440 & -3155 \\
& 10000 & -8280 & -8280 & -8280 & -8280 & -8280 & -8280 & -8280 & -8280 \\
& 0 & 4192 & 5361 & 6531 & 688 & 1409 & 2750 & -1020 & -593 \\
& 15000 & -8280 & -8280 & -8280 & -8280 & -8280 & -8280 & -8280 & -8280 \\
\hline 0 & -2681 & -2447 & -2213 & -3381 & -3237 & -2970 & -3723 & -3637 \\
& 3000 & -5175 & -5175 & -5175 & -5175 & -5175 & -5175 & -5175 & -5175 \\
& 0 & 3140 & 3920 & 4699 & 803 & 1284 & 2177 & -335 & -50 \\
25 & 10000 & -5175 & -5175 & -5175 & -5175 & -5175 & -5175 & -5175 & -5175 \\
& 0 & 7297 & 8466 & 9636 & 3792 & 454 & 5854 & 2084 & 2512 \\
& 15000 & -5175 & -5175 & -5175 & -5175 & -5175 & -5175 & -5175 & -5175 \\
\hline
\end{tabular}


Tablo 4. Farklı nominal ağırlıklara (lb/ft) sahip P-110 Tip Koruma Borusu ve farklı sıcaklık değişimleri için hesaplanan psi biriminden stres değerleri

\begin{tabular}{cccccccccc}
\hline$\Delta \mathrm{T}$ & $\begin{array}{c}\text { Derinlik } \\
\left({ }^{0} \mathrm{C}\right)\end{array}$ & 32 & 35 & 38 & 43.5 & 47 & 53.5 & 68 & 72 \\
\hline & 0 & -8476 & -8243 & -8008 & -917 & -9033 & -8765 & -9515 & -9434 \\
& 3000 & -10971 & -10971 & -10971 & -10971 & -10971 & -10971 & -10971 & -10971 \\
& 0 & -2656 & -1876 & -1097 & -4992 & -4511 & -3618 & -6131 & -5846 \\
53 & 10000 & -10971 & -10971 & -10971 & -10971 & -10971 & -10971 & -10971 & -10971 \\
& 0 & 1501 & 2671 & 3840 & -2003 & -1281 & 58 & -3711 & -3285 \\
& 15000 & -10971 & -10971 & -10971 & -10971 & -10971 & -10971 & -10971 & -10971 \\
\hline & 0 & -5785 & -5551 & -5318 & -6486 & -6342 & -6074 & -6828 & -6743 \\
& 3000 & -8280 & -8280 & -8280 & -8280 & -8280 & -8280 & -8280 & -8280 \\
40 & 0 & 35 & 814 & 1594 & -2301 & -1820 & -1820 & -3440 & -3155 \\
& 10000 & -8280 & -8280 & -8280 & -8280 & -8280 & -8280 & -8280 & -8280 \\
& 0 & 4192 & 5361 & 6531 & 687 & 1409 & 2750 & -1020 & -593 \\
& 15000 & -8280 & -8280 & -8280 & -8280 & -8280 & -8280 & -8280 & -8280 \\
\hline & 0 & -2680 & -2446 & -2212 & -3381 & -3237 & -2669 & -3723 & -3637 \\
& 3000 & -5175 & -5175 & -5175 & -5175 & -5175 & -5175 & -5175 & -5175 \\
& 0 & 3140 & 3920 & 4700 & 804 & 1285 & 2177 & -335 & -50 \\
& 10000 & -5175 & -5175 & -5175 & -5175 & -5175 & -5175 & -5175 & -5175 \\
& 0 & 7297 & 8446 & 9636 & 3792 & 4514 & 5854 & 2084 & 2511 \\
& 15000 & -5175 & -5175 & -5175 & -5175 & -5175 & -5175 & -5175 & -5175 \\
\hline \multirow{6}{*}{25} & & & & & & & & &
\end{tabular}

\section{Sonuç ve Öneriler}

Hesaplamalardan elde edilmiş olan bütün sonuçlar genel olarak değerlendirildiğinde çimento katk1 maddelerinden kaynaklı, çimentonun donma sürecindeki sıcaklık değişimlerinden dolayı oluşan yükler genellikle koruma borusu tasarımında daha fazla kompresif yüke neden olmaktadır. Kuyulardaki sıcaklık değişiminden dolayı oluşacak olan yükleri belirlemek ve tahmin etmek için kuyulardaki çeşitli faktörlerin bilinmesi gerekir. Gerilme değişimleri hakkında doğru hesaplama yapabilmek için ana faktör kesinlikle sıcaklık değişimidir. Bu hesaplamalarda, donma sürecinde (hidratasyon sırasında) is1 oluşumuna bağlı sıcaklık değişiminin önemi açıkça görülmektedir. Sonuçlar, daha yüksek sıcaklık değişimlerinde koruma boruları için her iki uçta da kompresif gerilmenin dominant olduğunu göstermektedir. Bununla birlikte, koruma borularının nominal ağırlığı, çapı ve uzunluğu gibi diğer faktörler termal yüklerin hesaplanmasında önemli bir rol oynamaktadır.

Çimento katkı maddelerinin çimento donma sürecinde oluşan sıcaklığa etkileri bulunmaktadır. Özellikle erken dönemde oluşacak olan sıcaklık değişimlerinin koruma borusu gerilmeleri açısından ek bir yük getireceği görülmektedir. Hesaplanan değerler her ne kadar koruma borularının dayanım değerleri içinde olsa da özellikle problemli, derin kuyularda ve gerilimin kompresiften çekme gerilmesine geçtiği kuyunun bölümlerinde bu etkinin de hesaplanması ileride karşılaşılabilecek çimento ve koruma borusu kaynaklı problemlerin değerlendirilmesi ve giderilebilmesi açısından önem arz etmektedir.

\section{Yazarların Katkısı}

Her iki yazarda eşit oranda katkıda bulunmuştur.

\section{Çıkar Çatışması Beyanı}

Yazarlar arasında herhangi bir çıkar çatışması bulunmamaktadır. 


\section{Araştırma ve Yayın Etiği Beyanı}

Yapılan çalışmada, araştırma ve yayın etiğine uyulmuştur.

\section{Kaynaklar}

[1] Bourgoyne A.T., Chevenert M.E., Millheim K.K., Young F.S. 1991. Applied Drilling Engineering. Richardson, Teksas, ABD.

[2] Rahman S.S., Chilingarian G.V. 1995. Casing Design Theory and Practice. Amsterdam, Hollanda.

[3] Nelson E.B., Guillot D. 2006. Well Cementing. Schlumberger Educational Services, Houston, Texas, ABD.

[4] Kutasov I.M., Eppelbaum L.V. 2015. Pressure and Temperature Well Testing. CRC Press, Taylor \& Francis Group LLC, Boca Ralton-London, New York, NW, ABD.

[5] Hewlett P. 2001. Lea's Chemistry of Cement and Concrete. 4th ed., Washington, D.C., Elsevier Ltd., ABD.

[6] Ravi K., Bosma M., Gastebled O. 2002. Improve the Economics of Oil and Gas Wells by Reducing the Risk of Cement Failure. IADC/SPE Drilling Conference, Dallas, Teksas, ABD.

[7] Romero J., Loizzo M. 2000. The importance of Heat on Cement Strength Development for Deep Water Wells. SPE Annual Technical Conference and Exhibition, Dallas, Teksas, ABD.

[8] Ozyurtkan, M.H. 2012. Designing impermeable cement slurry for high pressure and hot wells. Doktora Tezi, İstanbul Teknik Üniversitesi, Fen Bilimleri Enstitüsü, İstanbul.

[9] Asadov S., Ozyurtkan M.H. 2017. Modelling The Effect Additives on Exothermic Heat Development of Well Cement. 51st US Rock Mechanics / Geomechanics Symposium, San Francisco, California, ABD.

[10] Byrom T.G. 2007. Casing and Liners for Drilling and Completion. Gulf Publishing Company, Houston, Teksas, ABD. 